\title{
“I wanna be a SHIT-head!” Accepted and radical pedagogy
}

"It is only when the oppressed find the oppressor out and become involved in the organized struggle for their liberation that they begin to believe in themselves. This discovery cannot be purely intellectual but must involve action; nor can it be limited to mere activism, but must include serious reflection: only then will it be a praxis." (Freire 1996: 47)

"We wanna be free to do what we wanna do...and we wanna get loaded, and we wanna have a good time." (Wild Angels 1966)

An early review of Steve Pink's 2006 film Accepted points out that "what Accepted can't overcome is the tension at its core. The film-makers' desire to satirise the education system and to reveal just how it marginalizes anyone who falls through the cracks is undermined by their need to be upbeat and deliver a happy ending" (Macnab 2006: 46)

I argue in this essay that the film is characterised by other tensions that reveal a more complicated relationship with educational systems and pedagogic models than merely 'satirical'. For while the film undoubtedly targets educational elitism, at its heart are questions about the purpose and the nature of teaching and learning and, crucially, the possibility of genuinely radical pedagogy.

The South Harmon Institute of Technology, set up by protagonist Bartleby Gaines is originally intended as a ruse - a fictitious college whose acceptance enables him to evade the censure and disappointment of his parents, however, it becomes an experiment in Higher Education. As such it is useful to examine it in relation to other educational experiments and radical notions of pedagogy. To what extent, we can ask, does Accepted constitute a coherent 'counternarrative' (Giroux et al. 1996) through which mainstream pedagogy is indicted?

In this chapter I examine the ways in which the critical pedagogy represented in the film reflects the principles of radical pedagogues such as John Dewey, A.S. Neill and Paulo Freire. The oppositions established in the narrative are potent and the portrayal of the experiment as an exercise in social justice is romantically persuasive. Nevertheless, I conclude that the film, despite the triumphant resolution, cannot resolve some key tensions around the marketisation of higher education, the power relations involved in pedagogy and, ultimately, the limits of 'freedom'.

The story, in short, is this: Bartleby Gaines (Justin Long), rejected by every college he has applied to, invents a college and writes himself an acceptance letter in order to placate his parents. As the ruse escalates, and a simulation more elaborate than the website created by his friend Schrader (Jonah Hill) is 
required, he enlists other 'rejectees' to lease and renovate an old psychiatric hospital to stand for the 'South Harmon Institute of Technology'. Surprised by hordes of prospective students who have been automatically accepted by Schrader's website, Bartleby is about to end the fiction, but realises that the new arrivals are comrades in rejection and he perpetuates the illusion in order to provide a home for them. Banking their tuition fees, Bartleby realises that he has a responsibility to provide an educational experience and, dismayed by his tour of the stuffy, oppressive, nearby Harmon College, institutes a democratic model of education in which the students determine the curriculum. Bartleby's college is shut down when the expansionist Dean of Harmon College uncovers the subterfuge to parents and the authorities, but after an impassioned speech to the Board of Education the South Harmon Institute of Technology is allowed a probationary year to continue with its 'experimental programme'.

\section{Infantilisation and oppression}

Although not wishing to subscribe too heavily to nominative determinism, it is perhaps significant that Bartleby's name inevitably invokes Herman Melville's Bartleby the Scrivener. Melville's Bartleby is notable for his passive, implacable resistance to his employer's entreaties, but it is also possible to read this as a supreme exercise of freedom of will. Bartleby Gaines exhibits none of Bartleby the Scrivener's passivity, but he is a champion of resistance to orthodoxy and freedom from restraint. This contrast between liberty and restraint, exclusivity and inclusivity, is starkly drawn in an early scene with Van Horne, the Dean of the exclusive Harmon College: "Do you know what makes Harmon a great college? Rejection. The exclusivity of any university is judged primarily by the amount of students it rejects." And later, he outlines his plans for the 'Van Horne Gateway' - a symbolic entrance to the college, describing it as "a verdant buffer zone to keep knowledge in and ignorance out". This is (metaphorically) exemplary of what Paulo Freire calls the 'banking' model of education: "In the banking concept of education, knowledge is a gift bestowed by those who consider themselves knowledgeable upon those whom they consider to know nothing. Projecting an absolute ignorance onto others, a characteristic of the ideology of oppression, negates education and knowledge as processes of inquiry." (1996: 53) This opposition between exclusivity and inclusivity is a key binary in Accepted, through which a population of the oppressed is produced plausibly. And although, as Richard Shaull suggests, Freire's Brazilian illiterates are a far cry from a first world middle class, "...there are certain parallels in the two situations that should not be overlooked. Our advanced technological society is rapidly making objects of most of us and subtly programming us into conformity to the logic of its system. To the degree that this happens, we are also becoming submerged in a new 'culture of silence"' (Freire 1996: 15).

In order to progress with this argument, then, it is worth justifying the use of radical pedagogic models that have traditionally been concerned with deprived social groups and/or compulsory schooling. The materially 
comfortable middle class world of Accepted, and its dominant population of young adults, does not seem to meet these criteria, but I suggest that a critical approach based on such ideas is justified for two reasons. Firstly, the film. portrays a world in which the young adults are infantilised by their parents and by the education system. Secondly, it portrays a version of rejection and exclusion which is, at least, analogous with Freire's 'oppressed', Neill's "unfree child" (1968) and the recipients of "accidental" teaching and learning described by Dewey (1963)

To deal with the first point: it is not insignificant that the film opens with a scene in which Bartleby is taking photographs of his high school peers in order to create fake driving licences. The key piece of information on these licences is, of course, the date of birth, which, administratively, ages them into their early twenties, thus allowing them to be liberated from some of the restrictions of adolescence (in the US the national minimum drinking age is 21 and the purpose of the 'fake ID' is usually to enable the bearer to buy alcohol). The scene represents, in miniature, a desire for self-determination that can only be achieved through subverting the regulatory mechanisms that prevent 18 year olds from being 'adults'. By the same token, their lack of legitimate occupation of this classroom (signified by the outrage of Vice Principal Matthews who arrives to enjoy a 'women's fitness magazine') prefigures the significance of space in the film, specifically the configuration and boundaries of learning spaces.

In addition Bartleby's primary motive for creating his fictitious college is to avoid the disapprobation of his parents. In a key scene, with a high degree of emotional realism, when Bartleby tentatively moves towards admitting that he has been unsuccessful in all of his college applications, he faces confused disappointment from his mother and authoritative force from his father: "OK, cut the crap Bartleby. Society has rules, and the first rule is: you go to college; you want to have a happy and successful life - you go to college; if you want to be somebody - you go to college; if you want to fit in - you go to college." His mother's response, finally, is: "I knew we should have started preparing for college in Junior High - like your sister." There is little room for independence or maturity in this familial context of hope, expectation and obligation.

Parental authority then (and its attendant infantile positioning of offspring) performs key narrative functions in the film - it provides the motivation for Bartleby's deception and, later, when the deception is revealed, it is on the 'parents' day' fabricated by the Harmon College opposition, thus precipitating a rancorous exit with students being led away by disappointed mothers and fathers. Similarly, his best friend Schrader's path to Harmon College has been predetermined by the expectation that he will follow in his father's footsteps as "the fourth generation Schrader to go to Harmon College", and Abernathy (South Harmon's first student) tells his peers "When I got accepted here it was the first time my parents ever said they were proud of me!" 
Abernathy's poignant statement marks a turning point in the story - it is the moment at which Bartleby's motives shift from self-interest to care for others. And this commitment to care is invoked by recognition that the 'students' at his new 'college' are marginalised, excluded from Higher Education and, to deal now with the second point, 'oppressed'. Bartleby surveys the hall full of prospective South Harmon students and, in a watershed moment, recognises his kinship with this group of disenfranchised people:

"Just, show of hands, how many people applied to other colleges? And how many of you got in to the other places you applied to? Nobody...I know what it's like to be rejected - it sucks. Rejection blows - being said 'no' to - 'you know what, I'm sorry you're just not quite good enough - you didn't have enough extracurriculars, you didn't play enough tennis, you didn't study hard enough for your scores, so you're not going to make it. You know what, screw that! Shouldn't we all have the chance to be said yes to? At South Harmon we say 'yes' to you, we say 'yes' to your hopes, we say 'yes' to your dreams, we say 'yes' to your flaws! So welcome! Grab a room, grab a friend, grab yourself - we don't give a shit. Welcome to South Harmon Institute of Technology! And welcome to SHIT!"

The film, then, establishes a substantial population of dispossessed and disenfranchised. This includes Bartleby and his immediate circle - 'Hands', who lost his football scholarship because of a knee injury, Rory who pinned all her hopes on an application to Harvard and failed to get in, and Glen who managed to get zero on his SATs.

\section{The oppressed of Ohio}

Rejection and acceptance are central binaries in this film, and later I will show how an examination of a longer list of binaries can help us make sense of how the film manages its oppositions and contradictions. At this point, however, it is most relevant to highlight the way in which oppression is exercised not just through exclusion, but also inclusion. Harmon College, the prestigious, exclusive antithesis of South Harmon Institute of Technology, is shown to oppress the student body through symbolic and actual violence. The symbolic violence we witness from Bartleby's perspective when he reconnoitres classes in order to "figure this whole college thing out". Despite the rhetoric of the admissions counsellor who tells him that "here at Harmon College we offer a highly structured time-tested curriculum carefully designed to stimulate the young mind", the reality belies this: an economics lecture is pure "chalk and talk' - the students sleep, play with their phones or, in one case, panic ("Don't talk to me man! This is gonna be on the midterm and my whole life is riding on an 'A' in this class!"). Later Bartleby is bemused by being welcomed into an "overspill class" by a loudspeaker at the front of a lecture theatre, and when he later bumps into Monica, the object of his desire, who is a Harmon student, we are invited to share his bafflement at the administration of the curriculum: 
Monica: I'm taking a bunch of classes that I don't really care about. There was one though that I was dying to take, but I ended up not being able to, but you know, it's OK.

Bartleby: What was the one you wanted to take?

Monica: Photography... Well, see there's this photojournalism class, but they said it's only for journalism majors, and then there's this art photography class, but they said it's for fine arts majors, so my advisor said it would be best not to take either one, or something, because certain photography classes don't apply to a degree in photography.

Bartleby: Wow, that makes no sense at all.

Monica: I gotta go, I'm going to be late for my Ancient Roman History class.

The Harmon College students have no control over their education, but are shown submitting to/being coerced by a regime of power - the imposition of "...a series of standardized and ritualized pedagogic practices" (Cowden and Singh 2013: 53). Even when, as in Monica's case, the curriculum includes subjects that she is interested in, the regulatory system - the administration of education, makes it impossible for her to explore and enjoy those interests. This is Freire's 'banking model' of education in practice, vividly illustrated through the passive recipients of transmitted knowledge. And the indictment is more severe given the implication that this knowledge has little or no 'use value' (to invoke Marxist terminology), but rather constitutes something that has significant 'exchange value' when the students use their Harmon College degrees and fraternity memberships in order to gain economic advantage after graduation.

This symbolic violence is related to the actual violence that is meted out by the fraternity (BKE - 'Beta Kappa Epsilon'), for which Schrader is a 'legacy candidate'. This potential for violence is hinted at when Bartleby gains entry to the fraternity during 'rush'; (a period of recruitment) and slyly goads the fraternity president, Hoyt Ambrose:

"It's great, I love it here - all that sexual repressed energy....a lot of antiSemitism, but under the rug - I like it, I like the way you handle your business."

Schrader, as a 'legacy pledge' is the subject of humiliating hazing rituals, which involve being required to dress as a sperm and a hotdog, drink beer that has been spat in ("it's required for brotherhood") and, ultimately, suffer a beating in order to reveal the subterfuge of South Harmon.

What is established, then, is a picture of contemporary higher education in which young people inevitably lose, even if they appear to be winners; they are either losers through being rejected by the higher education system, or they are losers by being accepted, and then forced into submission by it. In the case of Hoyt Ambrose, the privileged, arrogant WASP who acts as Dean Van Horne's agent, the violence of the system has already reproduced itself, and the logic of exclusivity and market forces been internalised and 
normalised. The thesis is given explicit articulation by Schrader's Uncle Ben, who, in the guise of South Harmon's Dean, gives this lecture to Bartleby's parents:

"Look, we throw a lot of fancy words in front of these kids in order to attract them to going to school in the belief that they're going to have a better life, and we all know that all we're doing is breeding a whole new generation of buyers and sellers, buyers and sellers, pimps and whores, pimps and whores, and indoctrinating them into a lifelong hell of debt and indecision."

And at the end of the film, directly confronting Dean Van Horne with the abuses carried out by Harmon College, Bartleby indicts its: "100 years of tradition, but tradition of what? Of hazing kids and humiliating anyone who's a little bit different? Of putting so much pressure on kids they turn into these stress freaks and caffeine addicts".

\section{Opposition, resistance and rebellion}

It is useful to highlight the binaries which structure the meanings in this film concepts which characterise the two institutions (Harmon College, and South Harmon Institute of Technology) that stand in opposition to each other:

Rejection - Acceptance

Exclusivity - Inclusivity

The past/future - The present

Age - Youth

Theory - Practice

Stored information - Experience

Tradition - Novelty

Static - Dynamic

Knowledge - Ignorance

Restraint - Liberty

Institution is sovereign - Student/consumer is sovereign

Real - Fake

Parsimony - Generosity

Violence - Gentleness

Elite - Dregs

Authority - Rebellion

Exchange value - Use value

This set of oppositions provides a legitimation for the ethical mobilisation of radicalism in Bartleby's fake college. It is his recognition of the two kinds of oppression outlined above (oppression through exclusion and oppression through inclusion) that generates the pedagogic experiment (although these are not the terms of reference used). I have highlighted some of the more problematic oppositions, and in doing so I flag up some of the key issues for my conclusion, for it is worth considering how the list on the right of obvious virtues and ethically robust concepts also includes less noble elements, such as 'fakeness' and 'ignorance'. Some of these elements need to change their 
positions, or change their implications by the end of the film, thus producing some of the irreducible tensions.

But first let's examine the nature of the revolution and how it might be theorised. Having undertaken to 'care' for his new charges (motivated in part, perhaps, by the $\$ 1 \mathrm{~m}$ in tuition fee cheques that have arrived) Bartleby's investigation into mainstream education at nearby Harmon College results in bafflement and disillusionment. Uncle Ben, as is often the case, articulates the satire:

"What were you expecting? A renaissance of the human spirit? American education is in the shitter - you know why? Because people forgot the most important rule - college is a service industry."

At this point in the narrative, the object of Ben's indictment is the traditional curriculum as operated by Harmon College, but his invocation of the market sets up a tension that is unresolved, and cannot be resolved in this story. His reply to Bartleby's question "A service industry?" crystallises this issue: "As in 'serve us' as opposed to the other way around. Look you see all these kids out here? They all paid to come here, they all paid for an experience."

The film's response to this is to use it to legitimise a consultation process, initially with the core team, each of whom finds a 'passion' that has been denied to them via formal education, and then with the student body. This is a key plot point - a turning point in both the narrative, and in the philosophy of the South Harmon Institute of Technology; as Bartleby says: "All our lives we've been told what to learn. Well today the tide is gonna turn my friend, because today we're gonna ask the customer."

In the context of the binaries around which the film is structured, this is indeed a radical and potentially emancipatory turning point, but the word "customer" strikes a discordant note and invokes a contemporary debate about the relationship between universities and the marketplace - for Furedi, for example, "What is new and potentially disturbing about the marketisation of education is the attempt to recast the relationship between academics along the model of a service provider and customer" (2011: 2). Nevertheless, it also invokes Ken Robinson's notion of 'The Element' and the importance of "finding our own distinctive talents and passions" (2009: 28). Given that the ability of an individual to find his or her passion and develop it is not divorced from their social and economic circumstances, perhaps the opposition implied by my "nevertheless" is misplaced, and the tensions around market freedom and individual freedom are actually encapsulated here - something I will return to later.

\section{A revolutionary curriculum}

The South Harmon curriculum is a model of participatory practice - it consists of a giant white board onto which the students create and sign up to their own courses, and includes things such as 'Skateboading' (sic), 'Bumper Stickers' 
and 'The Art of Kissing'. There is an exuberance exhibited here, not just expressed through the alternative content, but also through the stylistic and formal modes of expression - the colours, the shapes, patterns and fonts which respond to the injunction at the top of the board: "What do you want to learn?"

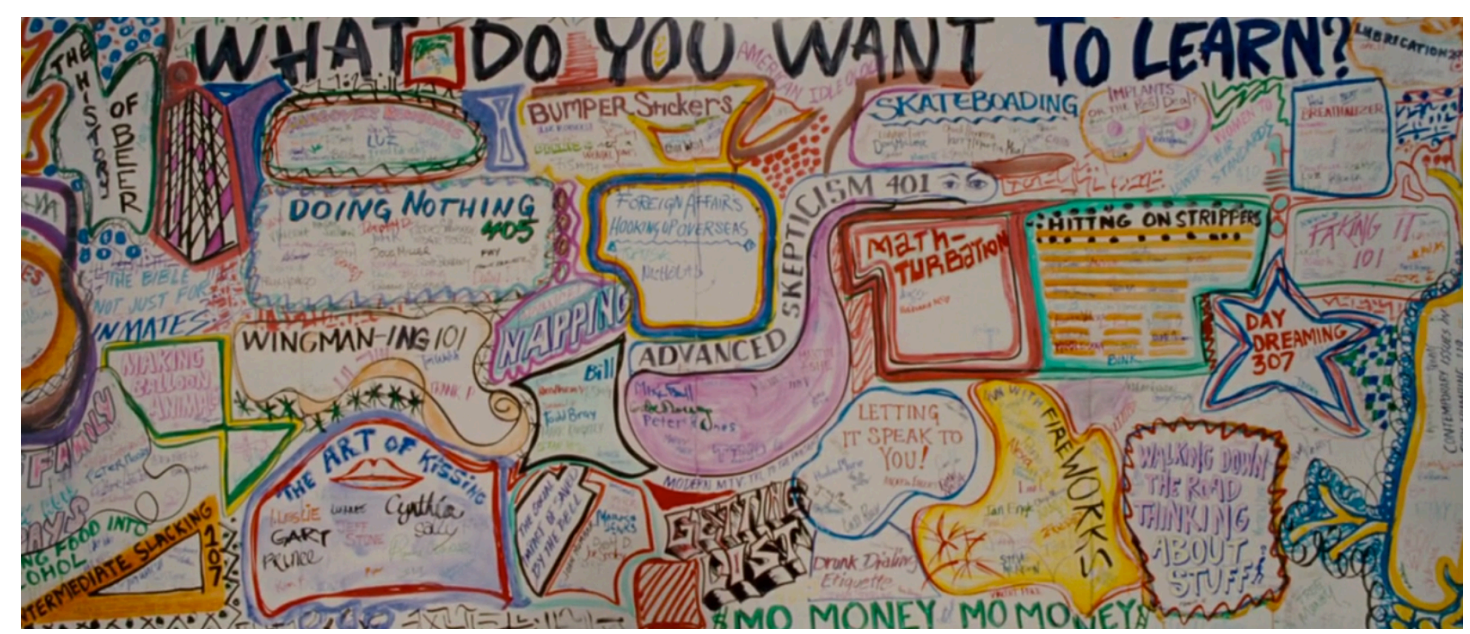

The South Harmon Institute of Technology curriculum

When Monica is shown around by Bartleby she asks:

"So this is your course guide?"

"Yeah, this is a new pilot programme, see the administration wanted us to create our own classes so we just write "em on the board."

" $\mathrm{B}$, there can't honestly be a class called 'Bulshitting 236'. What about 'The Decline and Fall of Chevy Chase'?"

"There's a wait list for that one."

"So you're telling me that there are no tests or essays or required reading or any of that nonsense?"

This innovative curriculum could be seen as the implementation of Freire's solution to oppressive pedagogy, when he says:

"The truth is, however, that the oppressed are not 'marginals', are not people living 'outside' society. They have always been 'inside' - inside the structure which made them 'beings for others'. The solution is not to 'integrate' them into the structure of oppression, but to transform that structure so that they can become 'beings for themselves'." (1996: 55)

We need to ask, then, to what extent does this curriculum model constitute structural transformation? The subjects have been generated by the students, and participation seems to be voluntary, although there is an assumption built into the question "What do you want to learn?" There is also no requirement to be assessed, and, therefore, no possibility of failure. It is seductive and it represents a seizing of power - the power to determine what is to be studied and, therefore, a freedom of sorts, although it is useful to recall Dewey here: "... for freedom from restriction, the negative side, is to be prized only as a 
means to a freedom which is power: power to frame purposes, to judge wisely, to evaluate desires by the consequences which will result from acting upon them; power to select and order means to carry chosen ends into operation..." (Dewey 1963: 63-64). Here we have a central tension between notional 'negative' freedom ('freedom from...') and an emancipatory freedom that may require some form of guidance or mentoring ('freedom towards...'?)

We should also bring into the discussion Furedi's point that "the commercialisation of education encourages institutions to provide what customers want rather than what they need to become truly educated" (2011: 4). The radical and the neo-liberal inhabit the same structural space in Accepted and there seems to be no contradiction.

\section{Tensions between new and old}

Radical as it seems, it is interesting to note that many of the subjects listed adopt the US numbering system which conveys something of the level and complexity of the course - ' 101 ' usually indicates an introductory course, for example. Given the newness of the institution, the curriculum and the student body, it seems unlikely that any prerequisites for 'Advanced Skepticism 401', 'Doing Nothing 405', or 'Day Dreaming 307' would have been acquired, so there is a sense in which a concept of developmental learning is being retained and performed. Even though this marks the inception of the experiment in democratic learning, it is difficult for the students to relinquish the signs of oppression - the labels that legitimise and authorise particular fields of knowledge as 'education'.

And despite the film's unequivocal advocacy of an alternative to Harmon College's traditional mode of delivery, it is uncertain how to convey the value of experiential non-directed learning. One montage sequence, for example, includes three scenes of Uncle Ben lecturing, each time to a larger group of students and culminating in him holding forth to students seating on and around the skateboarders' 'half pipe'. The setting is informal, the style of delivery is colloquial ("Taxes? I'll tell you about that nonsense - if you're rich the government'll protect every buck you make and every shit you take") but the pedagogic form is classical - Ben is like a peripatetic philosopher, lecturing to an open-air crowd. The third scene, which elicits spontaneous cheers is on the subject of learning:

"What is learning? It's paying attention. It's opening yourself up to this big ball of shit that we call life! And what's the worst that can happen? You get bit in the ass! Well let me tell you, my ass looks like hamburger meat, but I can still sit down!"

Increasingly the film relies upon the figure of Uncle Ben, who has genuine academic credentials we learn - at one point a student asks him to sign a copy of his book that she's found on ebay, and later it transpires that 30 years ago he was on the faculty at Harmon college. The 'revolutionary' or 'emancipatory' dimension to his pedagogy depends more on the message 
than the medium - he is, in many ways, a traditional pedagogue, lecturing to rapt students. Other elements in the montage, however, display autodidactic tendencies - Hands creating a priapic sculpture, Glen working in the kitchen, one student attempting to develop the ability to blow things up with mind control, another practising rock ' $n$ ' roll athleticism. The montage ends with a group of male students gazing at female students reclining in the pool; one says "I can't believe this is a class", thus summing up the problem here. Bartleby later makes a case for student-directed learning, but the film struggles to portray learning because, beyond freedom from restriction and personal predilections, it contains no theory of learning, but rather an antitheory. In this sense the conceptual foundations of the college have more in common with A.S. Neill than Paulo Freire - it plays out freedom from oppression rather than an engagement with oppression. Neill's founding principles for his fee-paying Summerhill school were based more on the value of individual flourishing and freedom from constraint than the development of critical faculties: "Books are the least important apparatus in a school. All that any child needs is the three R's; the rest should be tools and clay and sports and theatre and paint and freedom" (1968:38).

\section{A victory of (neo)liberalism}

The climax of the film puts the South Harmon Institute of Technology 'on trial' and, at its most persuasive, it effects a form of rhetorical transformation that effaces some of most problematic contradictions; it turns 'shit' into gold. Bartleby's bravura performance in this scene, in which the Ohio State Board of Education judges whether or not the college can be accredited, exhibits many of the qualities of Freire's 'radical': "committed to human liberation...this individual is not afraid to confront, to listen, to see the world unveiled. This person is not afraid to meet the people or to enter into dialogue with them. This person does not consider himself or herself the proprietor of history or of all people, or the liberator of the oppressed; but he or she does commit himself or herself, within history, to fight at their side" (1996: 21). When accused by Van Horne of being a "criminal" Bartleby rounds on the oppressor and the panel in a lengthy speech:

"You know what? You're a criminal, 'cause you rob these kids of their creativity and their passion - that's the real crime! What about you parents? Did the system really work out for you? Did it teach you to follow your heart, or just to play it safe - roll over? What about you guys? Did you always want to be school administrators? Dr. Alexander, was that your dream? Or maybe no, maybe you wanted to be a poet, maybe you wanted to be a magician or an artist. Maybe you just wanted to travel the world. Look, I lied to you, I lied to all of you and I'm sorry... but out of that desperation something happened that was so amazing. Life was full of possibilities, and isn't that what you ultimately want for us, as parents I mean, is possibilities? Well we came here today to ask for your approval and something just occurred to me - I don't give a shit! Who cares about your approval? We don't need your approval to tell us that what we did was real, cause there are so few truths in this world that when you see one, you know it, and I know that it is a truth that real learning took 
place at South Harmon, whether you like it or not, it did, 'cause you don't need teachers or classrooms or fancy highbrow traditions or money to really learn. You just need people with a desire to better themselves, and we got that by the shitload at South Harmon. So you can go ahead, sign your forms, reject us and shoot us down and do whatever you gotta do, it doesn't really matter at this point, because we'll never stop learning, and we'll never stop growing, and we'll never forget the ideals that were instilled in us at our place, 'cause we're SHIT-heads now, and we'll be SHIT-heads forever, and nothing you can say or do or stamp can take that away from us, so go, go ahead!"

As Macnab says, in the review quoted at the beginning of this chapter, "it is hard not to warm to a film that roots so strongly for losers - and does so with such spirit and good humour" (2006: 46) and this scene exemplifies the pleasure in the triumph of the underdog (Dean Van Horne is booed like a pantomime villain). The chair of the board, Dr Alexander in granting South Harmon Institute of Technology a probationary year in which to continue its experiment (an in a way that would gain the applause of Ken Robinson) says: "...the true purpose of education is to stimulate the creativity and the passions of the student body, and in that regard you have certainly succeeded", but what, we might ask, is entailed in regulating this probationary period?

The final sequence shows new students arriving at the start of term (the banner "Welcome Shitheads!" now denuded of its rebellious freight) and Uncle Ben now lecturing to a group of admiring students in a classroom - the medium outweighing the message: "This is not your orientation, this is your disorientation. You have been orientated for years". Bartleby bids his, now admiring, parents goodbye, and Schrader announces as he passes that he is about to teach 'Advanced Skepticism 401'. Meanwhile Rory, in the 'Rory Thayer Meditation Garden' (this is engraved on a stone) instructs a class in deep breathing, Glen gives rapid fire instructions in the kitchen about "pork tenderloin" and "balsamic vinegar glaze", and at the "Hands Holloway School of Art' (signified by more permanent signage) Hands invites a group of students to discover their passion for the arts, just as he did.

Ultimately, despite (we assume) a continuing commitment to widening participation through non-exclusive entry, the fake college that has become a real college must, inevitably have acquired many of the attributes that it previously opposed. The dynamic, student generated curriculum, for example, has become (literally, in the case of Rory's meditation garden) set in stone and the South Harmon Institute of Technology will become that which it purports to despise. Regulation will shape it, bureaucracy, administration will inexorably make it into 'an alternative state school' but not, any more a radical one. At the moment of its official sanctioning it has been diminished and compromised.

And given the tensions and contradictions outlined above, we should not be surprised - Accepted is a fantasy of radical democratic pedagogy which presents us with an imagined possibility, but even this fantasy is dependent 
upon the exchange value of a college education and an investment in a market-led concept of the student as consumer. Rather than the illusory 'liberal pedagogy' we see, at the end, 'neo liberal pedagogy' in which the 'student experience' takes precedence over all other considerations and the student 'founders' of the college are merely aping the authority of 'faculty'. It is a long way from Freire's concept of libertarian education:

"The raison d'etre of libertarian education... lies in its drive towards reconciliation. Education must begin with the solution of the teacher-student contradiction, by reconciling the poles of the contradiction so that both are simultaneously teachers and students" (1996: 53).

\section{References}

AMSLER, S. 2013. Criticality, Pedagogy and the Promises of Radical Democratic Education. In: COWDEN, S. \& SINGH, G. (eds.) Acts of Knowing: Critical Pedagogy In, Against and Beyond the University. New York, London: Bloomsbury.

COLLINI, S. 2012. What Are Universities For?, London, Penguin.

COWDEN, S. \& SINGH, G. 2013. Sat-Nav Education: A Means to an End or an End to Meaning? In: COWDEN, S. \& SINGH, G. (eds.) Acts of Knowing: Critical Pedagogy In, Against and Beyond the University. New York, London: Bloomsbury.

DEWEY, J. 1963. Experience \& Education, New York, Macmillan.

DEWEY, J. 1966. Democracy and Education, New York, Macmillan.

FREIRE, P. 1996. Pedagogy of the Oppressed, London, Penguin.

FUREDI, F. 2011. Introduction to the marketisation of higher education and the student as consumer. In: MOLESWORTH, M., SCULLION, R. \& NIXON, E. (eds.) The Marketisation of Higher Education and the Student as Consumer. Abingdon: Routledge.

KANPOL, B. 1999. Critical Pedagogy: An Introduction, Westport, Bergin \& Garvey.

KEOHANE, M. 1970. A.S. Neill: Latter-Day Dewey? The Elementary School Journal, 70, 401-410.

MACNAB, G. 2006. Accepted (Film review). Sight and Sound, 16, 46.

NEARY, M. \& HAGYARD, A. 2011. Pedagogy of excess: an alternative political economy of student life. In: MOLESWORTH, M., SCULLION, R. \& NIXON, E. (eds.) The Marketisation of Higher Education and the Student as Consumer. Abingdon: Routledge.

NEILL, A. S. 1968. Summerhill, Harmondsworth, Penguin.

ROBINSON, K. \& ARONICA, L. 2009. The Element: How finding your passion changes everything, New York, Viking. 